\title{
COMENTARIOS SOBRE LA HACIENDA PUBLICA DE LA DICTADURA DE PRIMO DE RIVERA
}

JOSEPH HARRISON

Universidad de Manchester

Han transcurrido dos décadas desde que se publicó la primera edición del trabajo pionero de Juan Velarde, Política económica de la Dictadura (1968). Esta obra, revisada sustancialmente en 1973, a pesar de su oportunidad, no le parece a muchos estudiosos suficientemente crítica del régimen de Primo de Rivera. Así, se profundiza más en las intenciones del dictador, en especial en las relaciones con las obras públicas, que en sus logros mensurables. Está claro que es útil saber cuántos millones de pesetas se asignaron a un programa específico de construcción de carreteras o de puesta en regadío; pero ¿cuánto dinero se había distribuido antes de que Argüelles pusiera fin a lo que él y la élite financiera consideraban un despilfarro? ¿Qué proporción de la multitud de Decretos que llenaron la Gaceta de Madrid se quedaron en letra muerta? Con la publicación del número especial de Cuadernos Económicos de ICE, 10 (1979), editado por Carlos Velasco con el título «Economía Política de la Dictadura de Primo de Rivera», se rectificó en alguna medida esta laguna historiográfica. Esta valiosa obra, todavía sin superar, contiene una serie de artículos excelentes sobre una diversidad de aspectos de la vida económica española durante el período 1923-30, en especial los de Nick Belford, sobre el sistema bancario; Fernando Eguidazu, sobre la crisis de la peseta y la caída de la Dictadura; Angel Melguizo, sobre la muy criticada política presupuestaria de Calvo Sotelo, y el estudio de Nicolás Ortega, sobre la política de regadíos y colonización. No es sorprendente, por tanto, que estos y otros historiadores que colaboraron en esta voluminosa obra reciban el debido homenaje en algunos de los artículos de esta reciente colección editada por Juan Velarde con el imprimátur del Instituto de Estudios Fiscales.

Pese a la persistencia de algunas enormes lagunas en nuestro conocimiento, la década de 1980 ha presenciado el despertar de un fascinante debate sobre la economía política del régimen de Primo de Rivera, al que este volumen del IEF contribuye de una manera valiosa y oportuna. Los historiadores económicos españoles han centrado especialmente su atención en el papel de instituciones tales como los bancos y el Estado. Por ejemplo, Gabriel Tortella y Jordi 
Palafox han subrayado la creciente participación en este período de las principales instituciones financieras en la industria española, en especial en aquellos sectores que se vieron favorecidos por un aumento del gasto público («Banca e industria en España, 1918-36», Investigaciones Económicas, 1983). Otros historiadores, como José Luis García Delgado, han puesto de relieve la actividad del régimen de Primo de Rivera al fomentar el proceso industrial a través de la política fiscal y de otros instrumentos monetarios (véase, especialmente, "La industria española en el primer tercio del siglo $\mathrm{xx}$, en J. M. Jover, ed., Los comienzos del siglo XX: la población, la economía, la sociedad, 1898$1931,1984)$. Inevitablemente, se ha planteado la siguiente pregunta: cuando en 1930 se produjo la recesión que llevó la crisis a la industria pesada y que generó un elevado nivel de desempleo en lugares tales como Bilbao, ¿qué importancia tuvo el denominado "error Argüelles» de la austeridad financiera? (véase el artículo de García Delgado en Papeles de Economia Española, 1980).

Recientemente se ha introdıcido en el debate un saludable clima de escepticismo con respecto a esos perennes temas que existen en cualquier discusión sobre la Dictadura: la política presupuestaria y la búsqueda de la autosuficiencia. Francisco Comín y Pablo Martín Aceña soștienen que, en una na. ción retrasada y empobrecida como la España de la década de 1920, el presupuesto tenía un efecto mínimo sobre la actividad económica global y que, además, no se disponía de los instrumentos necesarios. En el período 19201935, el sector privado fue mucho más importante que el sector público en la determinación de las alzas y bajas de la economía española (véase «La política monetaria y fiscal de la Dictadura y la Segunda República», Papeles de Economia Española, 1984). En general, es difícil no estar de acuerdo con esta opinión; sin embargo, teniendo en cuenta la fuerte concentración sectorial de las reformas infraestructurales de la Dictadura -metalurgia, cemento, construcción y ferrocarriles - se puede mantener, como Jordi Palafox, que entre 1927 y 1929, cuando el programa de inversiones estaba en marcha, las inversiones públicas fueron superiores a las privadas en una serie de industrias (véase «The Economy of Inter-War Europe: Fiscal Policy in Spain, 1929. 1936», artículo presentado en el Octavo Congreso Internacional de Historia Económica, Budapest, agosto de 1982). Una contribución igualmente valiosa para el debate procede de José María Serrano Sanz, quien, como Comín, tiene un artículo en el presente volumen. En la interpretación que hace este último de la política comercial española tras el arancel de Cambó de 1921.22 se ponen en duda las hipótesis que buscan explicar la política comercial subsiguiente en términos de una autarquía cada vez mayor (véase, especialmente, «La política arancelaria española al término de la primera guerra mundial: proteccionismo, arancel Cambó y tratados comerciales», en J. L. García Delgado, ed., La crisis de la Restauración, 1986). 
Es justo decir que el volumen editado por J. Velarde *, aunque algo desigual desde el punto de vista de la calidad y la originalidad, toma en consideración de manera más o menos completa los recientes acontecimientos en la historiografía económica de la Dictadura de Primo de Rivera. La extensión relativa de los demás tratados es la adecuada. Las finanzas públicas y la economía ocupan el mismo espacio, mientras que existen secciones más cortas tituladas «Las Instituciones» y "Política y Prensa».

Juan Velarde comienza con un artículo teleológico sobre los orígenes del corporativismo y del intervencionismo que caracterizaron el período de Primo de Rivera. Se hace una mención especial a Antonio Maura, mentor político del desafortunado Calvo Sotelo. Velarde fecha el declive de la economía de mercado en 1907, con la llegada al poder del gobierno largo de Maura (19071909). Asimismo, se debe considerar la difusión del catolicismo social, adoptado por el maurismo, el desarrollo del nacionalismo económico bajo la «influencia oscura» de Flores de Lemus y el regeneracionismo económico - no el de Santiago Alba, sino el de la «Revolución desde arriba» de Maura, un término acuñado ya en 1901-. En el estudio, menos prosaico, del programa legislativo de Primo de Rivera, realizado por Juan Antonio Santamaría, se nos dice que éste tuvo tres características esenciales:

a) Una mezcla de antiparlamentarismo, populismo y regeneracionismo orientados por la necesidad de un cambio estructural urgente, «para el pueblo, pero sin pueblo».

b) Una fuerte proclividad a detenerse en minucias (¡demasiado cierto!).

c) Una búsqueda enérgica de la eficiencia, que en la mayoría de los casos dio lugar a una serie de pesadillas burocráticas.

En un clásico ejemplo del proceso legislativo en acción, Francisco Comín analiza el intento frustrado de Calvo Sotelo de poner en vigor una contribución territorial rústica justa. Las bien conocidas propuestas del joven ministro de Hacienda, que fueron recibidas con una campaña de oposición orquestada por los terratenientes, se consideran técnicamente inadecuadas. No obstante, el frustrado reformador de impuestos fue algo ingenuo al depositar su confianza en «el verbalismo progresista del Dictador». Con el fracaso de las primeras iniciativas de Calvo Sotelo es válido preguntar, como Maximino Carpio: ¿poseía la Dictadura una política fiscal global? Carpio mantiene que el denominado presupuesto extraordinario simplemente eliminó algunas partidas del presupuesto ordinario, permitiendo así que el Gobierno presentara este último como si estuviera equilibrado. Según sus estimaciones, el presupuesto extraor-

* J. Velarde (ed.), La Hacienda Pública de la Dictadura de Primo de Rivera, 1923-30, Madrid, Instituto de Estudios Fiscales, 1986. 
dinario fluctuó entre el 6 y el 9 por 100 del presupuesto total. Volviendo al tema de la competencia técnica, César Albiñana hace una valoración más positiva de las reformas fiscales de la Dictadura. El hecho de que no se produjera ningún cambio básico en la estructura impositiva se debió a la oposición de los funcionarios, a las campañas de las inadecuadamente denominadas clases conservadoras y al bajo nivel de "comportamiento cívico" que existía en la sociedad española de la época. Sin embargo, gracias a los esfuerzos del eximio Flores de Lemus, el régimen dejó algunos textos y documentos legales muy bien redactados que sirvieron de base a reformas posteriores. De forma similar, Rafael Ortiz mantiene que el proyecto de Calvo Sotelo sobre el Impuesto sobre Rentas y Ganancias de 1926, si bien no tuvo éxito por una diversidad de razones, fue más que satisfactorio desde un punto de vista técnico. En este caso, los esfuerzos de Flores de Lemus, parte de su «reforma silenciosa», fueron premiados cuando, seis años más tarde, Carner adoptó muchos de los principios básicos de la Ley. Siguen dos artículos de Rafael Calvo Ortega y Joaquín del Moral sobre el tema, frecuentemente olvidado, de los impuestos locales. Calvo estudia el Estatuto Municipal de 1924 y encuentra sus orígenes en los proyectos de Canalejas (1910) y de González Besada (1918), con el reconocimiento obligatorio a Flores de Lemus. El artículo de Joaquín del Moral es un estudio espléndido de cómo las autoridades centrales de la España de finales del siglo xix dejaron sin fondos a los municipios, centrándose en la evolución de los consumos y en su eventual desaparición en el período 1905-11. En su estudio sobre el monopolio del petróleo (CAMPSA), Luis Pastor mantiene que, si bien Calvo Sotelo se decidió a establecer el monopolio principalmente por motivos fiscales, las cuestiones no fiscales fueron decisivas a la hora de elegir.

No es tan fácil encontrar algo en común en los artículos sobre la economía. Luis Germán muestra que la expansión del sistema bancario en Zaragoza en la década de 1920 se debió en gran medida a la adquisición de deuda pública. Las instituciones financieras locales poseían pocas acciones industriales en sus carteras. En su artículo sobre el suministro energético, Juan Hernández Andreu hace hincapié en la política de obras públicas de la Dictadura, a la que ve en el contexto de la expansión ininterrumpida del sector desde comienzos del siglo xx hasta la guerra civil. Juan Carlos Jiménez demuestra cómo la política industrial de la Dictadura revitalizó al Banco de Crédito Industrial, que, pese a su ilustre Consejo de Administración, había languidecido en los años posteriores a su fundación en 19.21. Victoriano Martín está de acuerdo con Pablo Martín Aceña (La política monetaria en España, 1919-1935, 1984) en que la evolución, en la década de 1920, del rudimentario sistema de control de cambios español, anterior a la creación del CROC y del COCM en 1930, fue ineficaz al estar basada en un diagnóstico equivocado de las verdaderas 
causas de la depreciación monetaria al sur de los Pirineos, a saber, la evolución de los mercados financieros. José María Serrano Sanz sostiene, en una continuación de sus trabajos anteriores, que tras la famosa Ley de Autorizaciones de 1922 de Bergamín, que provocó una serie de acuerdos con los principales proveedores y clientes comerciales de España que pusieron en juego la segunda columna del arancel, a la Dictadura le quedó un espacio de maniobra muy reducido para premiar a los proteccionistas que la apoyaban..Por su parte, Primo de Rivera estaba a favor de los acuerdos comerciales para fomentar las exportaciones agrícolas. Este artículo se complementa con el estudio de Francisco Constenla sobre el Consejo de Economía Nacional, parte fundamental del aparato burocrático del régimen, creado en marzo de 1924. Este autor argumenta de forma convincente que su carácter corporativista y poco representativo hizo imposible mantener un equilibrio entre los distintos sectores de la economía cuando tuvo que volver a redactar los acuerdos arancelarios.

De los diversos artículos que aparecen al final de la colección, el mejor es el de Eloy Fernández Clemente, quien realiza un buen estudio de la Confederación Sindical Hidrográfica del Ebro, uno de los proyectos favoritos del dictador, quien se vio a sí mismo como «el ejecutor del mensaje de Costa». Como buen aragonés, Fernández Clemente sale en defensa del hijo adoptivo de la región, Manuel Lorenzo Pardo, en «el escándalo del presupuesto». Quizá el IEF le preste atención y conceda una beca a un joven investigador para que estudie el valioso material que queda por leer en la biblioteca y en el archivo de la CHSE. ¿Por qué debe llevarse Flores de Lemus todos los aplausos? Ya es hora de que se haga justicia al genio inspirador de la Confederación del Ebro. En otro artículo, Miguel Angel Perfecto encuentra una gran dosis de pensamiento fascista italiano en el intento de Eduardo Aunós de intervenir en la cuestión social. Ismael Sanz Campos defiende que, pese a la amistad que existía entre Primo de Rivera, Alfonso XIII y Benito Mussolini, no fue siempre fácil traducir esta relación en dinero contante y sonante derivado del comercio internacional. Por último, María Dolores Saiz relata y contrasta la actitud de dos grandes periódicos, El Debate (a favor) y El Sol (en contra), respecto a la concesión del monopolio del petróleo.

Este libro contiene una importante colección de artículos, tanto para los estudiosos de la historia económica como para los de la Hacienda Pública. Hay que felicitar de nuevo al Instituto de Estudios Fiscales por su apoyo desinteresado a la investigación histórica. ¡Por favor, siga así! 